Research Paper

\title{
The Regulation of Matrix Metalloproteinase Expression and the Role of Discoidin Domain Receptor 1/2 Signal- ling in Zoledronate-treated PC3 Cells
}

\author{
Buket Reel $^{\varpi_{1}}$, Ceren Gonen Korkmaz¹, Mehmet Zuhuri Arun11, Gokce Yildirim¹, Deniz Ogut1, Aysegul \\ Kaymak $^{1}$, Serap Cilaker Micili², Bekir Ugur Ergur ${ }^{2}$ \\ 1. Department of Pharmacology, Faculty of Pharmacy, Ege University, Bornova, Izmir, Turkey \\ 2. Department of Histology and Embriology, School of Medicine, Dokuz Eylul University, Inciralti, Izmir, Turkey
}

$\triangle$ Corresponding author: Buket REEL, Ph.D. Ege University Faculty of Pharmacy Department of Pharmacology 35100 Bornova-Izmir, TURKEY. Tel: +90 232 3113286. E-mail: buket.reel@ege.edu.tr

๑ 2015 Ivyspring International Publisher. Reproduction is permitted for personal, noncommercial use, provided that the article is in whole, unmodified, and properly cited. See http://ivyspring.com/terms for terms and conditions.

Received: 2015.05.18; Accepted: 2015.07.27; Published: 2015.08.28

\begin{abstract}
Discoidin Domain Receptors (DDR1/DDR2) are tyrosine kinase receptors which are activated by collagen. DDR signalling regulates cell migration, proliferation, apoptosis and matrix metalloproteinase (MMP) production. MMPs degrade extracellular matrix (ECM) and play essential role in tumor growth, invasion and metastasis. Nitrogen-containing bisphosphonates (N-BPs) which strongly inhibit osteoclastic activity are commonly used for osteoporosis treatment. They also have MMP inhibitory effect. In this study, we aimed to investigate the effects of zoledronate in PC3 cells and the possible role of DDR signalling and downstream pathways in these inhibitory effects. We studied messenger RNA (mRNA) and protein expressions of MMP-2,-9,-8, DDR1/DDR2 type I procollagen (TIP) and mRNA levels of PCA-1, MMP-13 and DDR-initiated signalling pathway players including K-Ras oncogene, ERK1, JNK 1, p38, AKT-1 and BCLX in PC3 cells in the presence or absence of zoledronate (10-100 $\mu \mathrm{M})$ for 2-3 days.

Zoledronate $(100 \mu \mathrm{M})$ down-regulated DDR1/ DDR2, TIP mRNAs but did not change MMP-13 (collagenase-3) mRNA. However, zoledronate up-regulated MMP-8 (collagenase-2) mRNA. Zoledronate also inhibited mRNA expressions of K-Ras, ERK1, AKT-1, BCLX and PCA-1; but did not change JNK1, p38 mRNA levels. Zoledronate $(100 \mu \mathrm{M})$ supressed DDR1/DDR2, TIP expressions; and gelatinase (MMP-2/MMP-9) expressions/activities. Conversely, zoledronate up-regulated MMP-8 expression in PC3 cells.

Zoledronate down-regulates MMP-2/-9 expressions in PC3 prostate cancer cells. DDR1/DDR2 signalling and DDR-initiated downstream Ras/Raf/ERK and PI3K/AKT pathways may at least partially responsible for MMP inhibitory effect of zoledronate.
\end{abstract}

Key words: Discoidin domain receptor, MMP, cancer, bisphosphonate, zoledronate, cell culture

\section{Introduction}

Prostate cancer is the one of the most leading cause of cancer-related death in men in the world. Despite the pharmacological or surgical therapeutic strategies which reduce testosterone levels, the cancer frequently progresses androgen-independently to a metastatic phenotype [1]. Therefore, it is essential to establish new potential targets for the therapy.
Collagen is a major constituent of extracellular matrix (ECM) and also is a signalling molecule [2]. The recently described cell surface receptors for collagen are Discoidin Domain Receptors (DDR1/DDR2). DDRs represent a family of tyrosine kinase receptors which are activated by collagen $[3,4]$. Activation of DDR1/DDR2 triggers downstream sig- 
nalling pathways and plays essential role in cell differentiation, proliferation, migration and contributes to carcinogenesis $[5,6]$. Abnormal DDR function was recently shown in various human cancers $[7,8]$. Accordingly, DDR signalling has been suggested to be a key potential target in cancer therapy.

Ras mutations cause activation of downstream effector pathways which are well characterized as Ras/Raf/MEK/ERK and PI3K/AKT cascades [9]. These pathways regulate gene expression programs that promote cell growth, proliferation and survival. DDR signalling was reported to activate Ras/ERK MAPK and PI3K/AKT cascades in human cancers [8, 9].

Matrix metalloproteinases (MMPs) are a family of zinc-dependent proteolytic enzymes which degrade ECM components, including collagen. [10]. MMP up-regulation and excess matrix degradation can lead to inflammation, uncontrolled cell proliferation, angiogenesis, invasion and metastasis [11, 12]. High MMP activity was noticed in various cancers $[13,14]$. Similarly, MMP inhibitors were known to suppress tumor incidence, tumor growth and metastasis in prostate cancer $[15,16]$.

DDRs enhance tumor cell adhesion, tumor growth, invasiveness and shorten patient survival by stimulating MMP activity and MMP-mediated cell proliferation and migration $[17,18]$. However, the role of DDRs in the regulation of MMP secretion and activity in prostate cancer remained to be elucidated.

Nitrogen-containing bisphosphonates (N-BPs) which inhibit osteoclastic bone resorption are commonly used for the treatment of osteoporosis. Besides, NBPs exert antitumoral effects by suppressing MMP activity in cancer cells and prostate cancer patients [19-22].

The inhibitory effects of N-BPs on Ras/ERK and PI3K/AKT signalling pathways were demonstrated in human cancer cells and endothelial cells [22-24]. However, the effects of N-BPs on DDR signalling and downstream signalling pathways in the regulation of MMPs in prostate cancer cells are not fully understood yet.

In the present study, we aimed to investigate the effects of zoledronate which is the most potent N-BP in PC3 androgen-resistant prostate cancer cells and to clarify the possible role of DDR signalling and DDR-associated downstream molecular pathways in these effects.

\section{Materials and Methods}

\section{Materials}

Zoledronate (zoledronic acid monohydrate) in liquid form $(4 \mathrm{mg} / 5 \mathrm{ml}$ vial $)$ is kindly given from
Mustafa Nevzat A.S. (Istanbul, Turkey). Cell culture media (DMEM Ham's F12), fetal bovine serum (FBS) and L-glutamin were obtained from Gibco Cell Culture, CA, USA. Electrophoresis reagents were purchased from Sigma, USA. The enhanced chemiluminescence (ECL) plus reagent were from Amersham (Amersham, UK). Molecular weight marker (PageRuler Plus Prestained Protein Ladder) was obtained from Thermo Scientific, USA. Primary antibodies were detailed in Table S1.

\section{Cell culture}

PC3 cell line was kindly gift by Dr. K.S. Korkmaz, Ege University, Izmir, Turkey (The cell line were obtained from American Type Culture Collection). Cells were routinely cultured in DMEM Ham's F12 medium supplemented with 5\% FBS, 1\% penicillin/streptomycin $(5 \mathrm{mg} / \mathrm{ml})$ and $1 \%$ L-glutamine (200 $\mathrm{mM}$ ) in a humidified atmosphere containing 5\% $\mathrm{CO}_{2}$ at $37^{\circ} \mathrm{C}$. Cells were treated in the presence of $10 \mu \mathrm{M}$ or $100 \mu \mathrm{M}[23,25]$ zoledronate for 2 or 3 days. Untreated cells were kept as control in complete medium for the same period of time. At the end of the treatment period, both control and zoledronate-treated cells were collected and stored in $-80^{\circ} \mathrm{C}$ for further investigations.

\section{Cell lysis and protein extraction}

For protein extraction, cells were resuspended in $250 \mu \mathrm{l}$ of lysis buffer (20mM HEPES $\mathrm{pH}=7.4,0.1 \%$ Triton X-100, $0.2 \mathrm{mM}$ EDTA, $300 \mathrm{mM} \mathrm{NaCl}$ ). Cells then were collected from culture plates and transferred to Eppendorf tubes. Incubated on ice and centrifuged at $13.000 \mathrm{rpm}$ for 30 minutes and cleared supernatants were collected. Protein concentration in lysates were measured by using Quant-IT protein assay kit (Invitrogen, USA) according to the kit manual.

\section{Western blotting}

Under standard conditions, $20 \mu \mathrm{g}$ of protein from each cell extract was load to 10\% SDS-PAGE gels and separated by electrophoresis. Then, gels transferred to PVDF membrane (Amersham, UK) by semi-dry transfer blotter (VWR, V20-SDB, Austria). PVDF membranes were blocked with blocking solution (PBS-T -Phosphate Buffer Saline-solution containing $10 \%$ dry milk and $0.1 \%$ Tween 20) for 10 minutes. Primary and secondary antibody incubations were carried out using PBS-T containing 0.5\% dry milk at $4^{\circ} \mathrm{C}$ overnight and immunoblotted with primary antibodies. Primary antibodies used were rabbit antibodies specific for DDR1 (1:1000), DDR2 (1:1000), MMP-2 (1:1000), MMP-8 (1:1000), MMP-9 (1:1000), TIP (1:1000), and mouse antibody specific for 
$\beta$-actin (1:10000). Membranes were developed using ECL plus reagent for $5 \mathrm{~min}$, and photographed by Fusion FX7 (Vilbert Lourmat, France) at chemiluminesence. Optical density of blotting images for each protein was quantified by ImageJ software (ImageJ 1.46r, National Institute of Health, USA) and was normalized with $\beta$-actin.

\section{Gelatin zymography}

Zymograpy samples were normalized with protein concentration of each sample and loaded into $7.5 \%$ polyacrylamide gels containing $2 \mathrm{mg} / \mathrm{ml}$ gelatin and were subjected to electrophoresis. Following electrophoresis, SDS was removed from the gels by washing in $2.5 \%$ Triton X-100. Gels then were incubated at $37^{\circ} \mathrm{C}$ for $48 \mathrm{~h}$ in incubation buffer $(50 \mathrm{mM}$ Tris- $\mathrm{HCl}, \mathrm{pH} 8.0,50 \mathrm{mM} \mathrm{NaCl}, 10 \mathrm{mM} \mathrm{Ca} 2 \mathrm{Cl}$, and $0.05 \%$ Triton X-100). After the incubation period, gels were stained in $0.2 \%$ Coomassie Brilliant Blue. Images of the gels were photographed by using Fusion FX7. Gelatinase activity was detected as clear bands on dark backgrounds. Densitometric analysis of bands was performed using ImageJ software. Gelatin substrate digestion levels were quantified as relative proteinase activity (area $\mathrm{x}$ optical density/mg protein).

\section{Real time quantitative PCR}

PC3 cells were collected and total RNA was extracted from control and zoledronate-treated $(100 \mu \mathrm{M})$ cells for 3 days according to total RNA extraction kit (Quiagen RNA Easy Kit, USA) protocol. Total RNA concentrations were determined using a Nanovette Beckman Coulter DU 730 Spectrophotometer (Beckman Coulter, USA). cDNA was synthesized by random priming using Roche cDNA synthesis kit (Transcriptor High Fidelity cDNa Synthesis Kit, Roche, USA) and reactions were performed using a QuantiTect Reverse Transcription Kit (Qiagen, USA, 100 ng RNA per reaction) and Roche LC 480 Real-Time PCR (Roche, Germany) with primers for PCA1, MMP-2, MMP-8, MMP-9, TIP, Akt-1, BCLX, ERK1, JNK1, p38, $\mathrm{K}-$ Ras $4 \mathrm{~A}, \mathrm{~K}-\mathrm{Ras} 4 \mathrm{~B}$ and 36B4 which is housekeeping gene. Primers were detailed in Table S2.

\section{Immunocytochemistry}

PC3 cells were routinely cultured in DMEM Ham's F12 medium as mentioned above. Cover slips were placed into 6-well plates and $1 \mathrm{ml}$ of medium and $1 \mathrm{ml}$ of cell suspension were added on to the each cover slip in the plates and plates were shaken gently. Then, PC3 cells were allowed to adhere on coverslips for 24 hours in a humidified atmosphere containing $5 \% \mathrm{CO}_{2}$ at $37^{\circ} \mathrm{C}$. After incubation period, $1 \mathrm{ml}$ of medium was added on to the adhered cells. Adhered cells from zoledronate group were treated with 100 $\mu \mathrm{M}$ zoledronate. Some of the coverslips were kept as untreated for obtaining control cells. Control and zoledronate-treated cells were incubated for 72 hours (3 days) in a humidified atmosphere containing 5\% $\mathrm{CO}_{2}$ at $37^{\circ} \mathrm{C}$. After 3 days, media of the cells were removed and cells were fixed using 96\% ethanol for 15 min. After removing ethanol, cells on the cover slips were treated with $10 \%$ formalin then rehydrated through alcohol series and washed with distilled water. Then, they were treated with trypsin solution (00-3008, Digest All 2A, Zymed, San Francisco, California, CA) for $5 \mathrm{~min}$ at $37^{\circ} \mathrm{C}$. Cells were incubated in a solution of $3 \% \mathrm{H}_{2} \mathrm{O}_{2}$ for 5 min to inhibit endogenous peroxidase activity; and following with normal serum blocking solution. Cover slips were again incubated in a humidified chamber for $18 \mathrm{~h}$ at $4^{\circ} \mathrm{C}$ with primary antibodies for TIP, DDR1, DDR2, MMP-2, MMP-8, MMP-9, thereafter with biotinylated IgG, and then with streptavidin conjugated to horseradish peroxidase for $15 \mathrm{~min}$ each prepared according to kit instructions (85-9043, Invitrogen, USA). Cover slips were finally stained with DAB (diaminobenzidine, 1718096, Roche, Mannheim, Germany) and counter-stained with Mayer's hematoxylin. Then images of cells were obtained by using a light microscope (Olympus BX-51, Tokyo, Japan) equipped with a high-resolution video camera (Olympus DP-71, Tokyo, Japan). Immunopositivity of each protein was evaluated using immunoscoring by two histologists, who were blinded to the treatment of the samples to prevent ascertainment bias. The immunoscoring procedures were performed semi-quantitatively, by considering the degree and number of positive cytoplasmic staining of cells and by scoring on a scale in the following range: negative (0), weak (1), moderate (2) and strong (3). A mean score was calculated for each sample. Then mean scores were used to categorize immunpositivity as weak $(<1.5)$ or strong $(>1.5)$.

\section{Statistical analysis}

All data are expressed as mean \pm S.E.M. Statistical analyses of the data were performed using SPSS software (IBM SPSS PASW Statistics 19 Fix Pack 1 Amos 19, Chicago, IL) for Microsoft Windows. Fold changes in mRNA levels were calculated by using the Delta-Delta Ct method with 36B4 as an internal control. The statistical analysis of the significance between groups was carried out using paired Student's t-test. Chi-square test was used to evaluate the statistical difference of imunostaining between the groups. Difference was considered significant at $\mathrm{p} \leq 0.05$. 


\section{Results}

\section{Effects of zoledronate on DDR1 and DDR2 expressions}

We investigated the effects of zoledronate on DDR1 and DDR2 expressions by western blotting. Zoledronate $(100 \mu \mathrm{M})$ significantly decreased DDR1 expression compared to control cells at day 2 and day 3 (Fig. 1A), whereas zoledronate $(10 \mu \mathrm{M})$ did not affect DDR1 expression at either time point. Zoledronate $(100 \mu \mathrm{M})$ significantly reduced DDR2 expression at day 3 but not day 2 (Fig. 1A). However, DDR2 expression was not affected by zoledronate (10 $\mu \mathrm{M})$ at either day. We also evaluated expression levels of DDR1 and 2 by staining DDR1 and 2 immunocytochemically and by scoring immunopositivities semiquantitatively. Consistent with the western blotting findings, immunocytochemical results showed that expressions of DDR1 and 2 significantly were decreased in $100 \mu \mathrm{M}$ zoledronate-treated cells compared to control cells at day 3 (Figs. 1B and 1C). These results demonstrated that zoledronate inhibited both DDR1 and DDR2 signalling in PC3 cells.
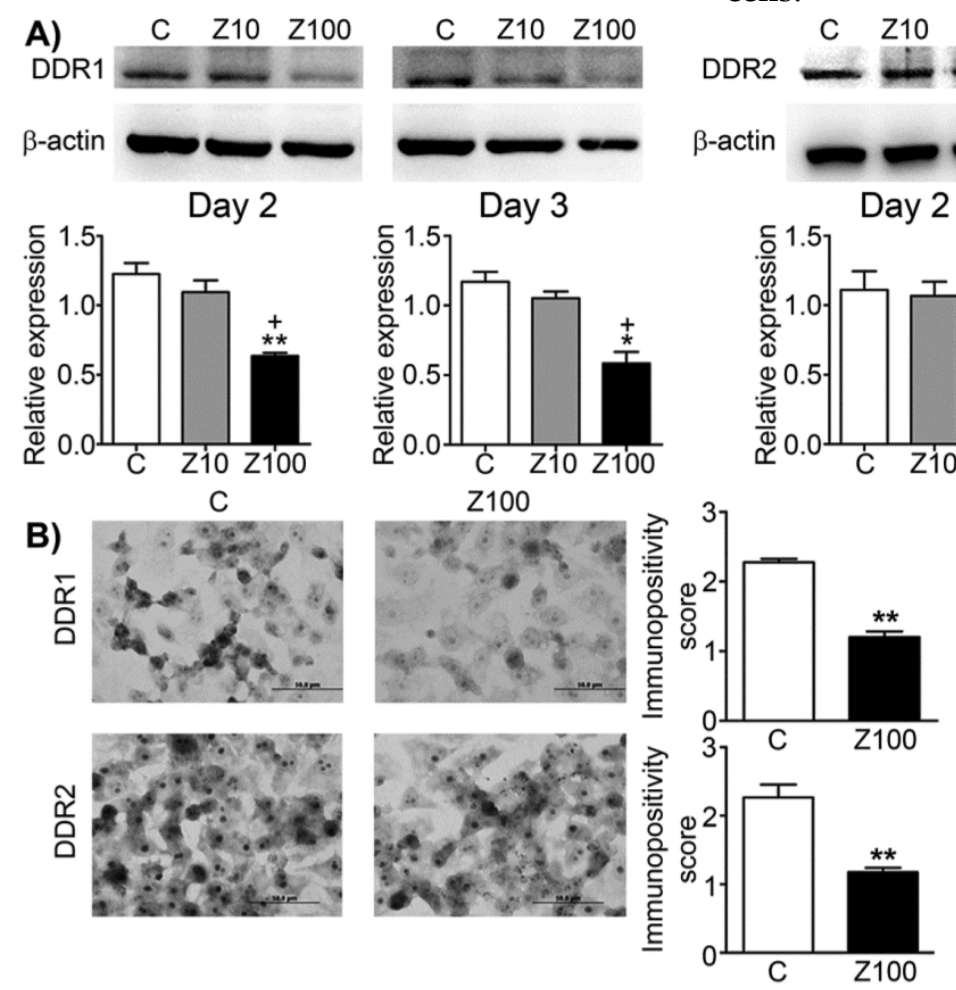

\section{Effects of zoledronate on expressions and ac- tivities of gelatinases}

We examined both gelatinase (MMP-2; gelatinase A and MMP-9; gelatinase B) expressions by performing gelatin zymography. Pro and active levels of MMP-9 and active levels of MMP-2 significantly declined in $100 \mu \mathrm{M}$ zoledronate-treated cells, but not in $10 \mu \mathrm{M}$ zoledronate-treated cells at day 3 (Fig. 2A). However, pro and active levels of both gelatinase enzymes were not affected by $10 \mu \mathrm{M}$ or $100 \mu \mathrm{M}$ zoledronate at day 2 (Fig. 2A). We also observed that MMP-2 production is less than MMP-9 production and pro level of MMP-2 was very low in PC3 cells.

Consistent with the zymographic analyses, western blotting analyses revealed the inhibitory effects of $100 \mu \mathrm{M}$ zoledronate treatment on MMP-9 expression at day 3 . Western blotting data showed that MMP-9 expression was significantly reduced in 100 $\mu \mathrm{M}$ zoledronate-treated cells, but did not change in 10 $\mu \mathrm{M}$ zoledronate-treated cells at day 3 (Fig. 2B).

Immunocytochemical staining indicated that both gelatinase expressions were down-regulated in $100 \mu \mathrm{M}$ zoledronate-treated cells (Fig. 2C).

These results implied, similar to the previous studies in different cancer cell lines, that zoledronate has inhibitory effects on gelatinase expressions in PC3 cells.
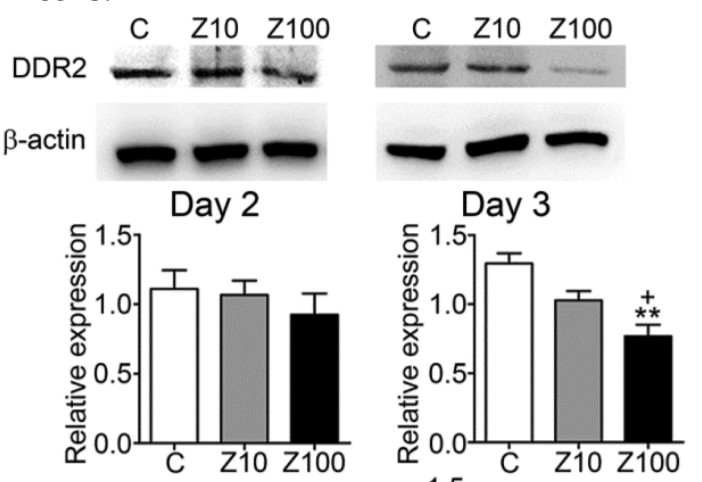

C)

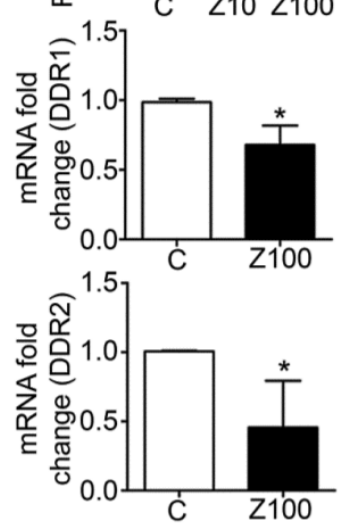

Fig. 1. Effects of 10 or $100 \mu \mathrm{M}$ zoledronate treatment on protein and $\mathbf{m R N A}$ expressions of DDR1 and DDR2. A) DDR1 and DDR2 expressions on western blotting at day 2 or 3 and representative western blots. Relative expressions of DDR 1 and DDR2 were expressed as mean $\pm S . E . M$. ( $n=4) * P \leq 0.05$, $* * P \leq$ $0.01, C$ versus Z100; + $P \leq 0.05$, Z10 versus Z100; Paired Student's t-test. B) Immunopositivity scores of DDR1 and DDR2 and representative photomicrographs of $\mathrm{PC} 3$ cells stained with DDR1 or DDR2 antibodies immunocytochemically at day 3 . Immunopositivity scores were expressed as mean \pm S.E.M. ( $\mathrm{n}=4$ ) $* * P \leq 0.01, \mathrm{C}$ versus Z100 Chi-square test. C) DDR1 and DDR2 mRNA expressions at day 3. mRNA fold changes were expressed as mean $\pm S . E . M$. ( $n=4) * P \leq 0.05, C$ versus $Z 100$ Paired Student's t-test. C: Control, Z10: $10 \mu \mathrm{M}$ zoledronate, Z100: $100 \mu \mathrm{M}$ zoledronate. 
A)

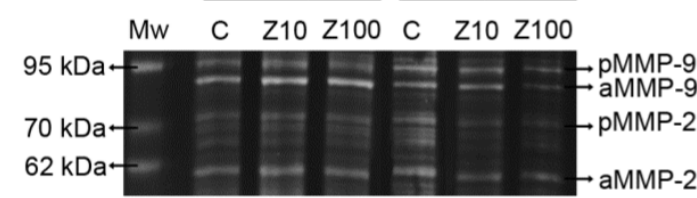

B)

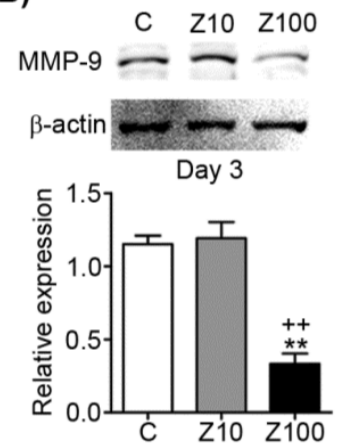

C)

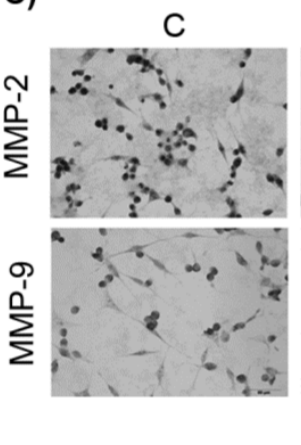

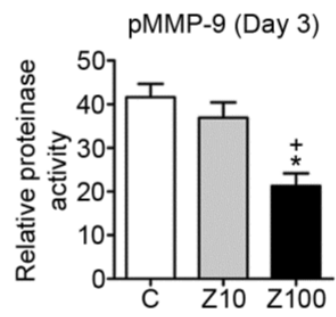

Z100

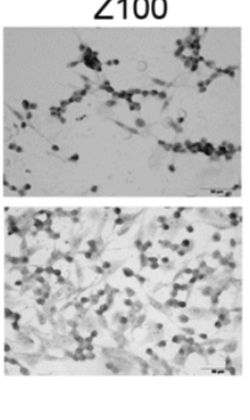

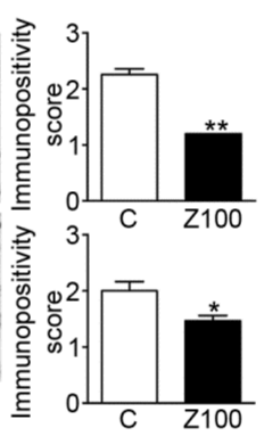

aMMP-9 (Day 3)
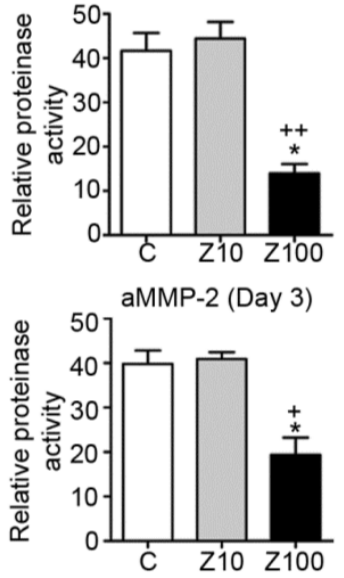

Fig. 2. Effect of 10 or $100 \mu \mathrm{M}$ zoledronate treatment on gelatinase (MMP-2 and -9) expressions and activities. A) Gelatinase expressions and activities by zymography at day 2 or 3 and representative zymogram. Relative proteinase activities of pro and active MMP- 9 and active MMP-2 were expressed as mean \pm S.E.M. $(n=4) * P \leq 0.05, C$ versus $Z 100 ;+P \leq 0.05,++P \leq 0.01, Z 10$ versus Z100; Paired Student's $t$-test. B) MMP-9 expression on western blotting and a representative western blot. Relative expression of MMP-9 was expressed as mean \pm S.E.M. $(n=4) * * P \leq 0.01 \mathrm{C}$ versus $Z 100$; $++P \leq 0.01 \mathrm{Z10}$ versus $Z 100$; Paired Student's $t$-test. C) Immunopositivity scores of both gelatinases and representative photomicrographs of PC3 cells stained with MMP-2 or MMP-9 antibodies immunocytochemically at day 3. Immunpositivity scores were expressed as mean \pm S.E.M. $(n=4) * P \leq 0.05$, ** $P \leq 0.01$, $C$ versus $Z 100$ Chi-square test. C: Control, Z10: $10 \mu \mathrm{M}$ zoledronate, Z100: $100 \mu \mathrm{M}$ zoledronate. C: Control, Z10: $10 \mu \mathrm{M}$ zoledronate, Z100: $100 \mu \mathrm{M}$ zoledronate.

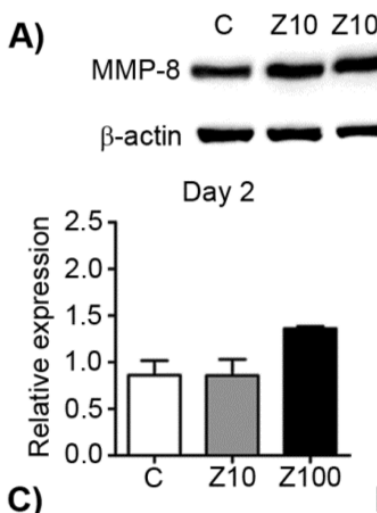

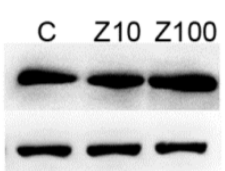

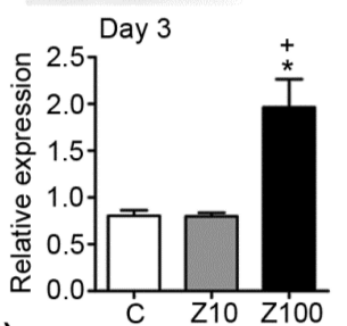

D)

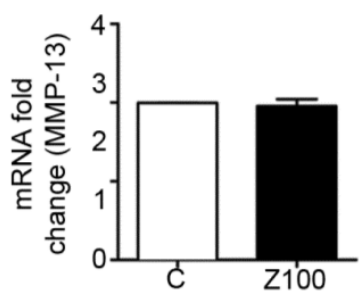

B)
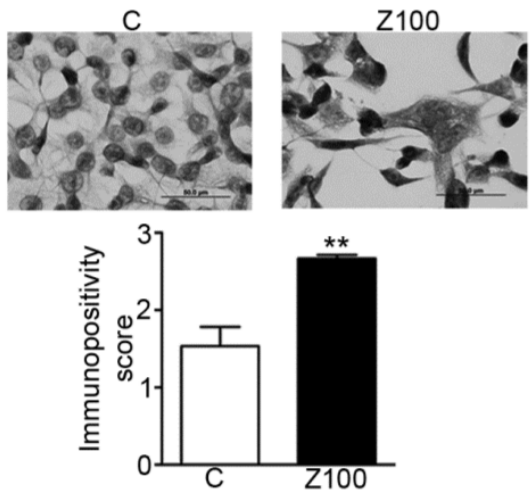

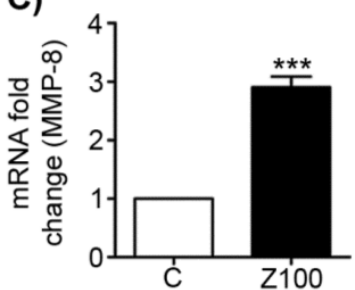

Fig. 3. Effects of 10 or $100 \mu \mathrm{M}$ zoledronate treatment on protein and mRNA expressions of collagenases. A) MMP-8 expression on western blotting at day 2 or 3 and representative western blots. Relative expressions of MMP- 8 were expressed as mean $\pm S . E . M$. ( $n=4) * P \leq 0.05, C$ versus $Z 100 ;+P \leq 0.05 Z 10$ vs Z100; Paired Student's t-test. B) Immunopositivity scores of MMP-8 and representative photomicrographs of PC3 cells stained with MMP-8 antibody immunocytochemically at day 3. Immunpositivity scores were expressed as mean \pm S.E.M. $(n=4) * * P \leq 0.01, C$ versus $Z 100$ Chi-square test. C) MMP-8 mRNA expressions at day 3. mRNA fold changes were expressed as mean \pm S.E.M. $(n=4) * * * P \leq 0.001 \mathrm{C}$ versus $Z 100$ Paired Student's $t$-test. D) MMP-13 mRNA expressions at day 3. mRNA fold changes were expressed as mean \pm S.E.M. $(n=4)$ C: Control, Z10: $10 \mu M$ zoledronate, Z100: $100 \mu M$ zoledronate.

\section{Effects of zoledronate on mRNA levels and expressions of collagenases (MMP-8 and MMP-13)}

To test the inhibitory effect of zoledronate on collagenases, we investigated the alterations of MMP-8 expressions in zoledronate-treated PC3 cells at day 2 or day 3 by western blotting. While exposure to $10 \mu \mathrm{M}$ zoledronate had no effect on MMP-8 expression level at day 2 and 3, $100 \mu \mathrm{M}$ zoledronate significantly caused MMP-8 up-regulation at day 3 in PC3 cells (Fig. 3A). Despite the tendency to increase in MMP-8 expression in $100 \mu \mathrm{M}$ zoledronate-treated cells at day 2 , this increment did not attain a signifi- 
cant level (Fig. 3A). Western blotting was confirmed by immunoscoring data for MMP-8 at day 3, which showed that $100 \mu \mathrm{M}$ zoledronate significantly increased MMP-8 expression at day 3 in PC 3 cells (Fig. 3B). $100 \mu \mathrm{M}$ zoledronate also caused up-regulation in mRNA levels of MMP-8 at day 3 in these cells (Fig. $3 C)$.

To test whether zoledronate may differentially modulate different collagenase enzymes, we also studied mRNA levels of MMP-13 by performing RT-PCR analyses. Distinctively from the effects of zoledronate on MMP-8, MMP-13 mRNA levels were not affected by $100 \mu \mathrm{M}$ zoledronate treatment at day 3 (Fig. 3D).

These results indicated that zoledronate affects each collagenase enzyme (collagenase 2; MMP-8 and collagenase 3; MMP-13) differently.

\section{Effects of zoledronate on type I procollagen mRNA levels and expressions}

In order to analyse the effects of zoledronate on TIP as the precursor of Type I collagen, we designed a series of experiments and studied the effects of zoledronate on protein and mRNA levels of TIP. 100 $\mu \mathrm{M}$ zoledronate caused down-regulation of protein and mRNA expressions of TIP, but $10 \mu \mathrm{M}$ zoledronate did not change these levels at day 3 (Fig. 4A). Similarly, immunocytochemical analyses confirmed these evidence completely in $100 \mu \mathrm{M}$ zoledronate-treated cells at day 3 (Fig. 4B). $100 \mu \mathrm{M}$ zoledronate also supressed mRNA levels of TIP in PC3 cells at day 3 (Fig. $4 C)$.

\section{Effects of zoledronate on Ras/ERK1 and PI3K/AKT signalling pathways and PCA- 1 in PC3 cells}

Collagen binding to DDRs triggers several downstream signalling pathways that can regulate the expression and proteolytic activity of MMPs in cancer cells. In this study, we addressed the question whether down-regulation of MMP expression by zoledronate correlates with inhibition of DDR-initiated signalling pathways including prosurvival Ras/Raf/ERK MAP kinase and PI3K/AKT cascades in PC3 cells. We therefore investigated the effects of $100 \mu \mathrm{M}$ zoledronate on mRNA expressions of proto-oncogenes K-Ras 4A, K-Ras 4B and prosurvival genes, ERK1, AKT-1 and antiapoptotic BCLX at day 3.

The results showed that $100 \mu \mathrm{M}$ zoledronate down-regulated mRNA levels of both isoforms of K-Ras; K-Ras 4A and K-Ras 4B (Fig. 5). Zoledronate also caused significant inhibition on the mRNA levels of ERK1, AKT-1 and BCLX (Fig. 5).

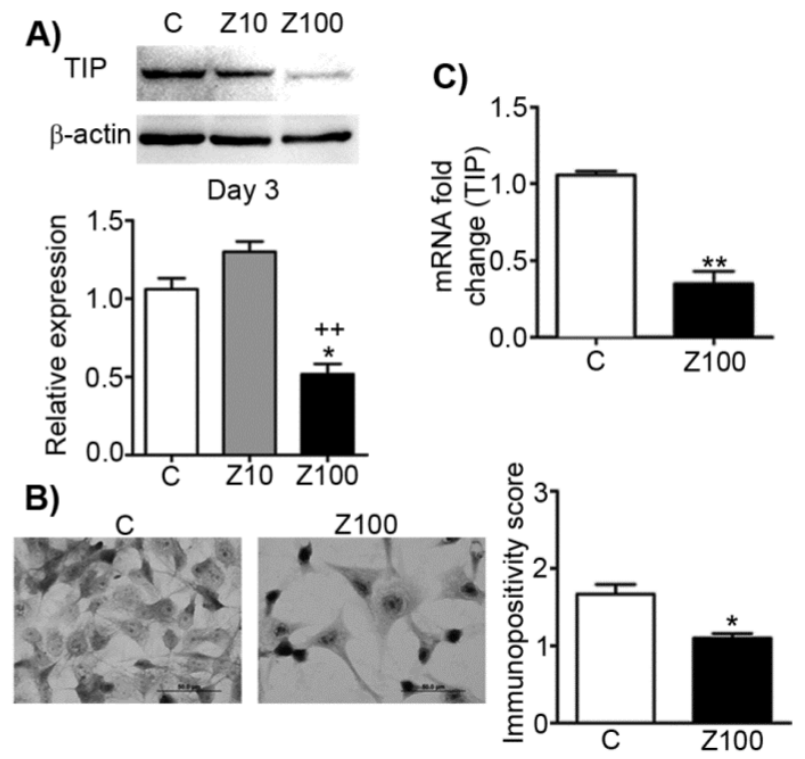

Fig. 4. Effects of 10 or $100 \mu \mathrm{M}$ zoledronate treatment on protein and mRNA expressions of TIP. A) TIP expression on western blot at day 2 or 3 and representative western blots. Relative expression of TIP were expressed as mean \pm S.E.M. $(n=4) * P \leq 0.05 C$ versus $Z 100$; $++P \leq 0.01, Z 10$ versus $Z 100$; Paired Student's $t$-test. B) Immunopositivity scores of TIP and representative photomicrographs of PC3 cells stained with TIP antibody. Immunpositivity scores were expressed as mean \pm S.E.M. $(n=4) * * P \leq 0.01 C$ versus $Z 100$ Chi-square test. C) TIP mRNA expressions at day 3. mRNA fold changes were expressed as mean \pm S.E.M. $(n=4) * * P \leq 0.01 \mathrm{C}$ versus $Z 100$, Paired Student's t-test. TIP: Type I procollagen, C: Control, Z10: $10 \mu \mathrm{M}$ zoledronate, Z100: $100 \mu \mathrm{M}$ zoledronate.
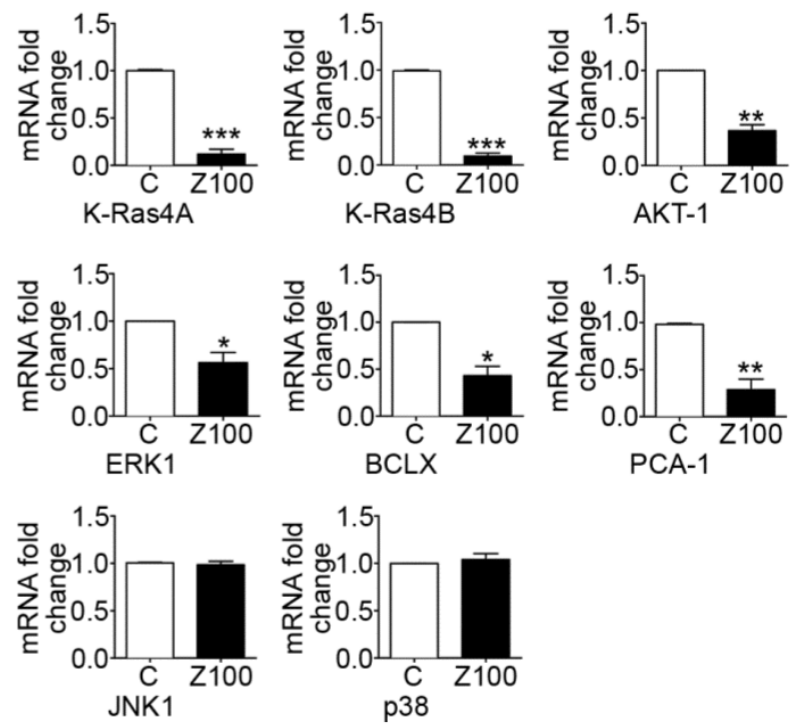

Fig. 5. Effects of $100 \mu \mathrm{M}$ zoledronate treatment on mRNA expressions of KRAS 4A, KRAS 4B, AKT-1, ERK1, BCLX, PCA-1, JNK1 and p38. Real-time PCR was performed on reverse-transcribed RNA isolated from control and $100 \mu \mathrm{M}$ zoledronate-treated cells at day 3. mRNA fold changes were expressed as mean \pm S.E.M. $(n=4) * P \leq 0.05$, $* * P \leq 0.01$, **** $P \leq 0.001, C$ versus Z100 Paired Student's t-test. C: Control, Z100: $100 \mu \mathrm{M}$ zoledronate.

We also examined the effects of zoledronate on PCA-1 mRNA levels as a potential marker gene for prostate cancer. Our results demonstrated that zoledronate supressed PCA-1 mRNA levels (Fig. 5). The evidence is consistent with decreased mRNA 
levels of antiapoptotic BCLX and indicates that zoledronate alleviated the aggressiveness of prostate cancer in association with inhibition of PCA-1 production.

\section{Effects of zoledronate on JNK1 and p38 signal- ling pathways in PC3 cells}

We considered the potential regulatory roles of other MAP kinase family members; JNK and p38 in DDR-induced MMP up-regulation in PC3 cells. To determine whether zoledronate inhibits JNK and p38 expressions, we assessed mRNA levels of these two MAP kinase enzymes in $100 \mu \mathrm{M}$ zoledronate treated cells and control cells at day 3. $100 \mu \mathrm{M}$ zoledronate changed neither JNK nor p38 mRNA expressions in PC3 cells at day 3 (Fig. 5).

\section{Discussion}

In the present study, we studied the possible effects of zoledronate in PC3 prostate cancer cell line. In the light of the evidence from the previous studies on N-BPs, we hypothesized that zoledronate can down-regulate MMPs in PC3 cells and DDR1/DDR2 signalling, downstream pathways may have a role in MMP inhibitory effect of zoledronate. Thereby, we have here assessed the expression of DDRs and gelatinases (MMP-2 and MMP-9), and major collagenase MMP-8 (collagenase-2) and MMP-13 (collagenase-3) in the presence or absence of zoledronate in PC3 cells for 2-3 days. We demonstrated that zoledronate inhibits DDR1/DDR2 signalling pathways and down-regulates MMP-2 and -9 expression and activities in PC3 cells.

Previous studies similarly have shown the inhibitory effects of N-BPs on the regulation of MMP synthesis and activity in various types of cancers. In an early study in bone metastatic prostate cancer cell line subclone PC3 ML cells, alendronate was shown to markedly reduced MMP-2 and -9 secretion [26]. Besides, a subsequent study demonstrated that alendronate reduced mRNA level and cellular level of MMP-2 in osteosarcoma cell lines dose-dependent manner [27]. In another study in osteosarcoma cell lines SaOS-2 and U2OS, risedronate which is a N-BP reported to inhibit expression and activity of MMP-2 and -9 and tumor cell invasion [28]. Accordingly, zoledronate was shown to induce down-regulation of MMP-2 and -9 activities and to inhibit cell invasion and lung metastasis in Euwing's sarcoma cell line [29]. In addition, another study in two breast cancer cell lines (MDA-MB-231 and MCF-7) with different metastatic potentials showed that zoledronate suppressed the expression of MMP-2, -9, the membrane type MT1- and MT2-MMP and prevented migration and invasion of cancer cells [20].
Surprisingly, we found that zoledronate markedly induced up-regulation of MMP-8 expression but did not change MMP-13 expressions in PC3 cells. Interestingly, MMP-8 was demonstrated to have protective role in cancer through its ability to reduce the metastatic potential of malignant cells in mice and human [30]. Similar beneficial effects of MMP-8 in cancer and metastasis were observed in breast cancer, tongue cancer and lymph node metastasis [31-33]. A recent study indicated that HGF (hepatocyte growth factor) variants inhibit proliferation, migration and invasion by inducing MMP-8 up-regulation and MMP-9 down-regulation in A549 human lung cancer cells [34]. Conversely, MMP-13 overexpression was demonstrated to induce tumor growth, invasion, and metastasis in numerous studies [35]. Despite to the diverse profile of effect, expression of both collagenases was shown to regulate by DDR receptors in several studies [36, 37].

In this context, we revealed first time that zoledronate stimulates an up-regulatory expression of MMP-8 which has a protective role against cancer in PC3 human prostate cancer cells. This effect also may contribute to the useful effects of zoledronate in the cancer therapy.

Unlike to our data regarding MMP-13, limited studies reported that N-BPs induces down-regulation on MMP-13 expression in cancer [38]. Various effects of zoledronate on MMP-8 and MMP-13 suggest that each collagenase has different expression pattern and substrate specify, and zoledronate affect each collagenase divergently. However, further investigations on MMP-8 will broaden our knowledge of the expression pattern and mechanisms regarding anticancer role of this collagenase.

The regulatory role of DDR signalling pathways in cancer progression was demonstrated in numerous cancer types $[7,8]$. In this study, we showed for the first time that zoledronate as the most potent bisphosphonate inhibits both DDR signalling in PC3 cells. This result pointed out the essential role of DDRs as novel therapeutic targets in the treatment of prostate cancer and also indicates that zoledronate down-regulates MMP expression at least partially by inhibiting DDR1 and 2 signalling and downstream pathways in PC3 cells.

The Ras family consists of four distinct Ras proteins (H-Ras, N-Ras and K-Ras splice variants: $\mathrm{K}-$ Ras4A and K-Ras4B). Ras protein mutations are associated with the activation of several effector pathways which mediate cell proliferation and malignancy $[9,39]$. DDR signalling was reported to initiate several downstream regulatory pathways including Ras/ERK MAPK and PI3K/AKT cascades in the cancer process $[3,8]$. Furthermore, N-BPs were 
demonstrated to inhibit Ras/ERK MAPK and PI3K/AKT signalling pathways in human cancer cells $[24,40]$.

To explore whether zoledronate inhibit DDR-initiated downstream pathways which cause stimulation of MMP expression under our experimental conditions, we examined the effects of zoledronate on Ras/ERK MAP kinase and PI3K/AKT pathways and antiapoptotic BCLX expression. This finding suggest that inhibition of DDR1/DDR2 signalling and DDR-initiated downstream prosurvival Ras/Raf/ERK and PI3K/AKT signalling pathways may associate with MMP-2 and MMP-9 down-regulation caused by zoledronate.

We also assessed the effects of zoledronate on mRNA levels of JNK and p38 genes from MAPK pathway in PC3 cells. We found that zoledronate did not affect mRNA levels of JNK and p38 genes. Similarly, a study on human gastric cancer cell line, SGC7901 reported that a new bisphosphonate derivative, CP induces gastric cancer apoptosis via activation of ERK1/2 signalling without affecting JNK and p38 signalling pathways [41].

However, a few studies demonstrated that NBs induce p38 signalling in cancer cells $[42,43]$.

According to our findings, zoledronate seems to inhibit DDR activation, without affecting JNK and p38 signalling pathways in PC3 cells. However, this finding needs further investigations, since we have not examined protein expressions of JNK and p38.

Furthermore, we examined the effects of zoledronate on PCA-1 expression in the present study. PCA-1 was recently described as potential marker gene for prostate cancer. High expression level of PCA-1 was notified to be positively correlated with invasiveness and severity of cancer [44]. In a study in DU145 prostate cancer cells, it was reported that PCA-1 transfection to the cells caused to increase the levels of both antiapoptotic BCLX and DDR1, which makes cell more invasive through MMP-9 up-regulation [45]. Similarly, in this study we demonstrated that zoledronate down-regulated PCA-1 mRNA expressions associated with mRNA expressions of BCLX and MMP-9 in PC3 cells. Similarly, Shimada et al. revealed that knockdown of the PCA-1 gene induced apoptosis through reducing BCLX expression in PC3 cells [45]. Furthermore, it was reported that PCA-1 regulates activity of DDR1 downstream pathway and PCA-1/DDR1 axis closely involved in malignant potential of androgen-independent prostate cancer cells [45]. In the line of these evidences, our results indicate that zoledronate may induce apoptosis of cancer cells and suppress invasion by inhibiting PCA-1 expression in PC3 cells.
To our knowledge, type I collagen is the most abundant fibrillar collagen and the component of bone matrix in mammals [35]. In the present study, we therefore evaluated the effects of zoledronate on type I procollagen in PC3 cells since collagen is the unique ligand of DDRs. Our results showed that zoledronate inhibited type I procollagen expression in parallel with DDR expression. Similarly, alendronate was reported to decrease plasma collagen levels in bone metastatic prostate cancer cell line PC3 ML cells-injected mice [26]. Our results suggest that while zoledronate inhibits activation of DDRs by collagen, it also prevent bone resorption and metastasis.

Although in vitro studies suggest that zoledronate may be efficient in prostate cancer, evidences from clinical studies are controversial. A clinical study reported that long-term zoledronate treatment reduces skeletal complications and attenuates bone pain in patients with bone metastases secondary to hormone-refractory prostate cancer. In the same study, researchers also stated that zoledronate is only the bisphosphonate to show significant reduction in skeletal complications [46]. Yuen et al reviewed clinical trials on prostate cancer patients with bone metastasis and reported that there was no difference between the treatment and the control groups in prostate cancer death, disease progression, radiological and PSA response [47]. Similarly, a study on patients with castration-sensitive prostate cancer and bone metastases reported that zoledronate did not affect the risk of skeletal-related events [48]. On the other hand, another recent study (ZEUS: Zometa European Study) demonstrated that zoledronate is ineffective for the prevention of bone metastases in high risk prostate cancer patients at 4 year [49]. However, further clinical and in vitro studies which enlighten the role of DDRs and MMPs in different stages of disease may increase the therapeutic value of bisphosphonates in the treatment of prostate cancer. While clinical trials of specific inhibitors for MMPs were unsuccessful in various cancers, knowledge of MMP functions in cancer has gradually increased in the last decade. Recent studies focused on novel regulatory roles of MMPs in cancer progression may cause to more effective therapeutical use of MMP inhibitors in cancer therapy in the future [50].

Taken together, the results from this study may provide new insights into the functions of DDR signalling and downstream pathways as novel therapeutic targets in the regulation of MMP expressions during the cancer cell invasion and metastasis. Our data may also add more learnings to underlying mechanisms of the anticancer effects of zoledronate in prostate cancer progression. 


\section{Supplementary Material}

Tables S1 and S2.

http://www.jcancer.org/v06p1020s1.pdf

\section{Abbreviations}

DDR: Discoidin Domain Receptor; ECM: Extracellular Matrix; MMP: Matrix metalloproteinase; MT-MMP: Membrane type MMP; N-BP: Nitrogen-containing bisphosphonate; PCA-1: Prostate cancer antigen-1; SEM: Standard error of mean; TIMP: Tissue inhibitor of matrix metalloproteinase; TIP: Type I procollagen.

\section{Acknowledgement}

We are greatly appreciated to Prof. Andrew C Newby for his valuable expert contributions and encouraging support.

\section{Author contributions}

$B R$ conceived and designed the experiments and wrote the paper. BR, CGK, MZA, GY, DO, AK performed the experiments. SCM and BEU performed immunocytochemical stainings and analysed the data. MZA and BR analysed the results. All authors read and approved final manuscript.

\section{Funding}

This research was supported by the Scientific Research Foundation of Ege University, Izmir, Turkey [13/ECZ/012 to Buket Reel].

\section{Competing Interests}

The authors have declared that no competing interest exists.

\section{References}

1. Baade PD, Youlden DR, Krnjacki LJ. International epidemiology of prostate cancer: geographical distribution and secular trends. Molecular nutrition \& food research. 2009; 53: 171-84.

2. Hou G, Vogel W, Bendeck MP. The discoidin domain receptor tyrosine kinase DDR1 in arterial wound repair. J Clin Invest. 2001; 107: 727-35.

3. Fu HL, Valiathan RR, Arkwright R, Sohail A, Mihai C, Kumarasiri M, et al. Discoidin domain receptors: unique receptor tyrosine kinases in collagen-mediated signaling. The Journal of biological chemistry. 2013; 288 : 7430-7.

4. Vogel WF, Abdulhussein R, Ford CE. Sensing extracellular matrix: an update on discoidin domain receptor function. Cellular signalling. 2006; 18: 1108-16.

5. Carafoli F, Hohenester E. Collagen recognition and transmembrane signalling by discoidin domain receptors. Biochimica et biophysica acta. 2013; 1834: 2187-94

6. Park HS, Kim KR, Lee HJ, Choi HN, Kim DK, Kim BT, et al. Overexpression of discoidin domain receptor 1 increases the migration and invasion of hepatocellular carcinoma cells in association with matrix metalloproteinase. Oncology reports. 2007; 18: 1435-41.

7. Borza CM, Pozzi A. Discoidin domain receptors in disease. Matrix biology : journal of the International Society for Matrix Biology. 2014; 34: 185-92.

8. Valiathan RR, Marco M, Leitinger B, Kleer CG, Fridman R. Discoidin domain receptor tyrosine kinases: new players in cancer progression. Cancer metastasis reviews. 2012; 31: 295-321.

9. Baines AT, Xu D, Der CJ. Inhibition of Ras for cancer treatment: the search continues. Future medicinal chemistry. 2011; 3: 1787-808

10. Nagase H, Visse R, Murphy G. Structure and function of matrix metalloproteinases and TIMPs. Cardiovascular research. 2006; 69: 562-73.

11. Lu P, Weaver VM, Werb Z. The extracellular matrix: a dynamic niche in cancer progression. The Journal of cell biology. 2012; 196: 395-406.
12. Polette M, Nawrocki-Raby B, Gilles C, Clavel C, Birembaut P. Tumour invasion and matrix metalloproteinases. Critical reviews in oncology/hematology. 2004; 49: 179-86.

13. Hadler-Olsen E, Winberg JO, Uhlin-Hansen L. Matrix metalloproteinases in cancer: their value as diagnostic and prognostic markers and therapeutic targets. Tumour biology : the journal of the International Society for Oncodevelopmental Biology and Medicine. 2013; 34: 2041-51.

14. Sun J. Matrix metalloproteinases and tissue inhibitor of metalloproteinases are essential for the inflammatory response in cancer cells. Journal of signal transduction. 2010; 2010: 985132.

15. Lokeshwar BL. MMP inhibition in prostate cancer. Annals of the New York Academy of Sciences. 1999; 878: 271-89.

16. Lokeshwar BL. Chemically modified non-antimicrobial tetracyclines are multifunctional drugs against advanced cancers. Pharmacological research : the official journal of the Italian Pharmacological Society. 2011; 63: 146-50.

17. Hou G, Vogel WF, Bendeck MP. Tyrosine kinase activity of discoidin domain receptor 1 is necessary for smooth muscle cell migration and matrix metalloproteinase expression. Circulation research. 2002; 90: 1147-9.

18. Ram R, Lorente G, Nikolich K, Urfer R, Foehr E, Nagavarapu U. Discoidin domain receptor-1a (DDR1a) promotes glioma cell invasion and adhesion in association with matrix metalloproteinase-2. Journal of neuro-oncology. 2006; 76: $239-48$

19. Corey E, Brown LG, Quinn JE, Poot M, Roudier MP, Higano CS, et al. Zoledronic acid exhibits inhibitory effects on osteoblastic and osteolytic metastases of prostate cancer. Clinical cancer research : an official journal of the American Association for Cancer Research. 2003; 9: 295-306.

20. Dedes PG, Gialeli C, Tsonis AI, Kanakis I, Theocharis AD, Kletsas D, et al. Expression of matrix macromolecules and functional properties of breast cancer cells are modulated by the bisphosphonate zoledronic acid. Biochimica et biophysica acta. 2012; 1820: 1926-39.

21. Facchini G, Caraglia M, Morabito A, Marra M, Piccirillo MC, Bochicchio AM, et al. Metronomic administration of zoledronic acid and taxotere combination in castration resistant prostate cancer patients: phase I ZANTE trial. Cancer biology \& therapy. 2010; 10: 543-8.

22. Tsubaki $\mathrm{M}$, Itoh $\mathrm{T}$, Satou $\mathrm{T}$, Imano $\mathrm{M}$, Komai $\mathrm{M}$, Ogawa $\mathrm{N}$, et al. Nitrogen-containing bisphosphonates induce apoptosis of hematopoietic tumor cells via inhibition of Ras signaling pathways and Bim-mediated activation of the intrinsic apoptotic pathway. Biochemical pharmacology. 2013; 85: 163-72.

23. Hasmim M, Bieler G, Ruegg C. Zoledronate inhibits endothelial cell adhesion, migration and survival through the suppression of multiple, prenylation-dependent signaling pathways. Journal of thrombosis and haemostasis : JTH. 2007; 5: 166-73

24. Riganti C, Castella B, Kopecka J, Campia I, Coscia M, Pescarmona G, et al. Zoledronic acid restores doxorubicin chemosensitivity and immunogenic cell death in multidrug-resistant human cancer cells. PloS one. 2013; 8: e60975.

25. Wu L, Zhu L, Shi WH, Zhang J, Ma D, Yu B. Zoledronate inhibits the proliferation, adhesion and migration of vascular smooth muscle cells. European journal of pharmacology. 2009; 602: 124-31.

26. Stearns ME, Wang M. Alendronate blocks metalloproteinase secretion and bone collagen I release by PC-3 ML cells in SCID mice. Clinical \& experimental metastasis. 1998; 16: 693-702.

27. Cheng YY, Huang L, Lee KM, Li K, Kumta SM. Alendronate regulates cell invasion and MMP-2 secretion in human osteosarcoma cell lines. Pediatric blood \& cancer. 2004; 42: 410-5.

28. Xin ZF, Kim YK, Jung ST. Risedronate inhibits human osteosarcoma cell invasion. Journal of experimental \& clinical cancer research : CR. 2009; 28: 105.

29. Odri G, Kim PP, Lamoureux F, Charrier C, Battaglia S, Amiaud J, et al. Zoledronic acid inhibits pulmonary metastasis dissemination in a preclinical model of Ewing's sarcoma via inhibition of cell migration. BMC cancer. 2014; 14: 169 .

30. Gutierrez-Fernandez A, Fueyo A, Folgueras AR, Garabaya C, Pennington CI, Pilgrim S, et al. Matrix metalloproteinase- 8 functions as a metastasis suppressor through modulation of tumor cell adhesion and invasion. Cancer research. 2008; 68: 2755-63.

31. Decock J, Hendrickx W, Vanleeuw U, Van Belle V, Van Huffel S, Christiaens MR, et al. Plasma MMP1 and MMP8 expression in breast cancer: protective role of MMP8 against lymph node metastasis. BMC cancer. 2008; 8: 77.

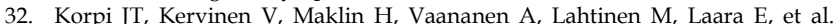
Collagenase-2 (matrix metalloproteinase-8) plays a protective role in tongue cancer. British journal of cancer. 2008; 98: 766-75.

33. Soria-Valles C, Gutierrez-Fernandez A, Guiu M, Mari B, Fueyo A, Gomis RR et al. The anti-metastatic activity of collagenase- 2 in breast cancer cells is mediated by a signaling pathway involving decorin and miR-21. Oncogene. 2014; 33: 3054-63.

34. Ramanujum R, Lin YL, Liu JK, He S. Regulatory expression of MMP-8/MMP-9 and inhibition of proliferation, migration and invasion in human lung cancer A549 cells in the presence of HGF variants. The Kaohsiung journal of medical sciences. 2013; 29: 530-9.

35. Ala-aho R, Kahari VM. Collagenases in cancer. Biochimie. 2005; 87: 273-86.

36. Afonso PV, McCann CP, Kapnick SM, Parent CA. Discoidin domain receptor 2 regulates neutrophil chemotaxis in 3D collagen matrices. Blood. 2013; 121: $1644-50$.

37. Xu L, Peng H, Wu D, Hu K, Goldring MB, Olsen BR, et al. Activation of the discoidin domain receptor 2 induces expression of matrix metalloproteinase 
13 associated with osteoarthritis in mice. The Journal of biological chemistry. 2005; 280: 548-55.

38. Yamashita J, Koi K, Yang DY, McCauley LK. Effect of zoledronate on oral wound healing in rats. Clinical cancer research : an official journal of the American Association for Cancer Research. 2011; 17: 1405-14.

39. Abubaker J, Bavi P, Al-Haqawi W, Sultana M, Al-Harbi S, Al-Sanea N, et al. Prognostic significance of alterations in KRAS isoforms KRAS-4A/4B and KRAS mutations in colorectal carcinoma. The Journal of pathology. 2009; 219: 435-45.

40. Marra M, Santini D, Meo G, Vincenzi B, Zappavigna S, Baldi A, et al. Cyr61 downmodulation potentiates the anticancer effects of zoledronic acid in androgen-independent prostate cancer cells. International journal of cancer Journal international du cancer. 2009; 125: 2004-13.

41. Wang HJ, Liu Y, Fan LQ, Han CL, Jiang $Y$, Cheng SJ, et al. A new bisphosphonate derivative, $\mathrm{CP}$, induces gastric cancer cell apoptosis via activation of the ERK1/2 signaling pathway. Acta pharmacologica Sinica. 2013; 34: 1535-44.

42. Milone MR, Pucci B, Bruzzese F, Carbone C, Piro G, Costantini S, et al. Acquired resistance to zoledronic acid and the parallel acquisition of an aggressive phenotype are mediated by p38-MAP kinase activation in prostate cancer cells. Cell death \& disease. 2013; 4: e641.

43. Merrell MA, Wakchoure S, Lehenkari PP, Harris KW, Selander KS. Inhibition of the mevalonate pathway and activation of p38 MAP kinase are independently regulated by nitrogen-containing bisphosphonates in breast cancer cells. European journal of pharmacology. 2007; 570: 27-37.

44. Konishi N, Nakamura M, Ishida E, Shimada K, Mitsui E, Yoshikawa R, et al. High expression of a new marker PCA-1 in human prostate carcinoma. Clinical cancer research : an official journal of the American Association for Cancer Research. 2005; 11: 5090-7.

45. Shimada K, Nakamura M, Ishida E, Higuchi T, Yamamoto H, Tsujikawa K, et al. Prostate cancer antigen-1 contributes to cell survival and invasion though discoidin receptor 1 in human prostate cancer. Cancer Science. 2007;: 071029163557002

46. Saad F, Gleason DM, Murray R, Tchekmedyian S, Venner P, Lacombe L, et al Long-Term Efficacy of Zoledronic Acid for the Prevention of Skeletal Complications in Patients With Metastatic Hormone-Refractory Prostate Cancer. JNCI Journal of the National Cancer Institute. 2004; 96: 879-82.

47. Yuen KK, Shelley M, Sze WM, Wilt T, Mason MD. Bisphosphonates for advanced prostate cancer. The Cochrane database of systematic reviews. 2006;: CD006250.

48. Smith MR, Halabi S, Ryan CJ, Hussain A, Vogelzang N, Stadler W, et al. Randomized controlled trial of early zoledronic acid in men with castration-sensitive prostate cancer and bone metastases: results of CALGB 90202 (alliance). Journal of clinical oncology : official journal of the American Society of Clinical Oncology. 2014; 32: 1143-50.

49. Wirth M, Tammela T, Cicalese V, Gomez Veiga F, Delaere K, Miller K, et al. Prevention of Bone Metastases in Patients with High-risk Nonmetastatic Prostate Cancer Treated with Zoledronic Acid: Efficacy and Safety Results of the Zometa European Study (ZEUS). European urology. 2014.

50. Shay G, Lynch CC, Fingleton B. Moving targets: Emerging roles for MMPs in cancer progression and metastasis. Matrix biology : journal of the International Society for Matrix Biology. 2015; 44: 200-6. 